\title{
Microleakage in class $V$ cavities restored with composite resin using chitosan and consepsis as the cavity disinfectants
}

\begin{abstract}
Aim: To compare the influence of chitosan and consepsis on bonding of composite resin to dentin and cementum.

Materials and methods: Class V cavities were prepared on 20 extracted mandibular molars. The cavities in the experimental groups were pre-treated with a scrub of cavity disinfectants followed by application of bonding agent. Preparations without cavity disinfectants served as control. After the cavities were restored with resin composite (G-Aenial Universal Flo), the specimens were subjected to dye penetration. Statistical analysis was performed using Chi-square test and Fisher Exact test.

Results: There was no statistically significant difference in the leakage values between the Chitosan and Consepsis group. There was a statistically significant difference between the microleakage score of the bonding system with or without the cavity disinfectant.

Conclusion: Chitosan was found to be similar to Consepsis, an established cavity disinfectant in preventing microleakage and was found not to interfere with bonding of composite resin to either dentin or cementum, holds potential to be used as an effective cavity disinfectant prior to restoration with composite resin.
\end{abstract}

Keywords: chitosan, cavity disinfectant, chlorhexidine gluconate, dentin-bonding resin, microleakage
Volume 2 Issue 3 - 2017

\section{Kanika Varshneya, Shiny Benjamin, Naveen DN, Mohan T Nainan, Nirupama DN, Ashok $\mathrm{KB}$}

Department of Conservative Dentistry and Endodontics, Vydehi Institute of Dental Sciences and Research Centre, India

\author{
Correspondence: Kanika Varshneya, Department of \\ Conservative dentistry and Endodontics, Vydehi Institute of \\ Dental Sciences and Research Centre, Bangalore, Karnataka, \\ India, Tel +91 9901064313, Fax 080-28416199, \\ Email kanika.varshneya@gmail.com
}

Received: February 19, 2017 | Published: May 08, 2017
Abbreviations: $\mathrm{CEJ}$, cemento enamel junction; $\mathrm{NaOCl}$, sodium hypochlorite; $\mathrm{CHX}$, chlorhexidine

\section{Introduction}

The setting reaction of resin composites involves polymerization shrinkage that may lead to the formation of a contraction gap at the tooth restoration interface. This gap can result in the passage of bacteria, fluids, or ions between the cavity wall and the resin composite, a process which is known as microleakage. ${ }^{1}$ Previously, many new bonding systems have been introduced to reduce the size and incidence of gap formation following placement of a resin composite restoration. Even then, microleakage, especially at the dentin (cementum) aspect of restoration, remains a problem of clinical significance. ${ }^{2-4}$ Microleakage has been demonstrated as a factor in hypersensitivity, secondary caries and pulpal pathology. ${ }^{5}$

The success of the restorative procedures depends on the effective removal of infected dentin, prior to the placement of the restorative material. The main problem associated with microleakage can be magnified by residual caries, as a consequence of failure to mechanically remove the infected tooth structure. ${ }^{6}$ Histological and bacteriologic studies have shown that very few teeth are actually sterile after cavity preparation and that bacteria left in the cavity preparation could survive for longer than a year after removal of the carious dentin, it is therefore important to eliminate any remaining bacteria that may be left behind in the smear layer, at the enamel-dentin junction, or in the dentinal tubules. ${ }^{7}$ Thus, application of disinfectants after cavity preparation and before restoration is fast gaining acceptance. It eliminates risks due to bacterial activity. ${ }^{89}$ However, there is concern about the interference of cavity disinfectants with dentin bonding agents, since they have been shown to alter the sealing ability of the hydrophilic resin to the dentin. ${ }^{10}$ Contrary to this concern, has been a suggestion that cavity disinfectants can improve the sealing ability of dentin bonding agents by rehydrating the conditioned dentin. The purpose of this study was to evaluate the effect of two cavity disinfectants on the microleakage of a non-rinse dentin-bonding system, Clearfil SE Bond (Kuraray).

\section{Materials and methods}

Twenty freshly extracted human mandibular molars, free of cracks, caries and restorations, were used in the study. The teeth were scraped of any tissue remnants and stored in $2.6 \% \mathrm{NaOCl}$ (Sodium hypochlorite) solution (VIP, Vensons India, Bangalore, India) for 15 minutes each and rinsed under running water. They were later cleaned with pumice and stored in normal saline (NS, Fresenius Kabi, Goa, India) at $40^{\circ} \mathrm{C}$ until use (Figure 1).

Standardized class V cavity preparations were made on the facial and lingual surfaces of each tooth, with no 245 straight fissure bur (Mani, India) in a high speed hand piece (NSK Pana Air, Japan) utilizing water-spray coolant. Standardized preparations were obtained by making cavity preparations approximately $2 \mathrm{~mm}$ wide, $2 \mathrm{~mm}$ deep and $3 \mathrm{~mm}$ long, paralleling the cemento-enamel junction (CEJ). The depth of the preparations was assessed using a periodontal probe (GDC, India). The gingival halves of the preparation were extended $1 \mathrm{~mm}$ below the CEJ (Figure 2). Prepared surfaces were 
rinsed with distilled water for 20seconds followed by air drying for 20 seconds a two-way syringe. The teeth were then randomly divided into two groups:

Group I consisted of ten teeth (20 cavity preparations);10 cavity preparations were treated with $\mathrm{CHX}$ (chlorhexidine) based cavity disinfectant solution (Consepsis, Ultradent USA), followed by the application of a dentine bonding system (Clearfil SE Bond, Kuraray, Japan). Remaining 10 cavities were bonded without chlorhexidine pre-treatment and were used as control.

Group II consisted of ten teeth (20 cavity preparations); 10 cavity preparations were treated with chitosan based cavity disinfectant solution (Everest Biotech, Bangalore), followed by the application of a dentine bonding system (Clearfil SE Bond, Kuraray, Japan). Remaining 10 cavities were the control i.e. without application of chitosan.

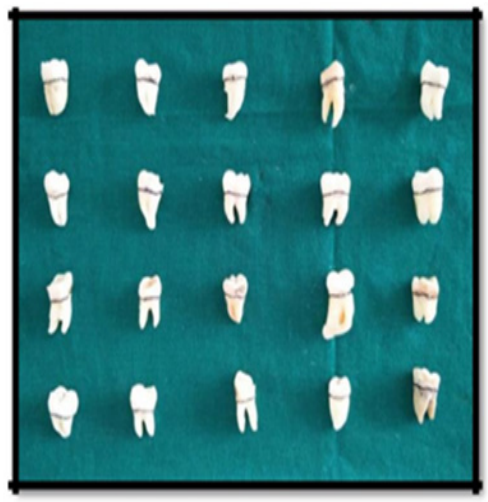

Figure I Twenty freshly extracted human mandibular molars.

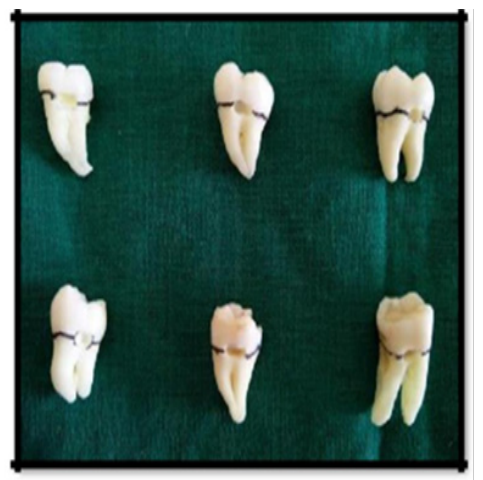

Figure 2 Standardized class $V$ cavity preparations were made on the facial and lingual surfaces of each tooth.

In each of the experimental groups, cavity disinfectant was applied with a sterile brush applicator (Dochem, Shanghai, China) and scrubbed for 20seconds; excess disinfectant was removed by lightly air drying for five seconds.

After cavity disinfection, the dentin bonding system (Clearfil SE Bond, Kuraray, Japan) was applied as per the manufacturer's instructions. Primer was applied to the cavity floor and agitated for 20 seconds and gently air dried. A layer of bonding resin was applied to the preparation with a brush, spread gently with air and cured for 10 seconds. The cavity preparations were restored with a resin composite (G-Aenial Universal Flo, GC, Tokyo, Japan) by light curing for 60seconds. The cavosurface margins were then finished with a finishing bur and 3M USA discs. All the teeth were stored in distilled water for 24 hours, at $37^{\circ} \mathrm{C}$, and subjected to 1,000 thermal cycles between water baths of $50^{\circ} \mathrm{C}$ and $550^{\circ} \mathrm{C}$, with a dwell time of 30 seconds. The teeth were then subjected to dye leakage tests.

All the specimens were covered with two coats of nail varnish leaving $1 \mathrm{~mm}$ of the tooth-restoration margin and the root apices were sealed with modelling wax. The specimens were then immersed in $0.5 \%$ basic fuchsin dye (NICE Chemicals Pvt Ltd, India), in separate sealable glass vials (Borosil, India), at $37^{\circ} \mathrm{C}$ for 24 hours. After staining, the teeth were rinsed in water and dried using two-way syringe, the radicular parts of the teeth were then cut $4.5 \mathrm{~mm}$ below the CEJ using diamond discs. Coronal portion of the teeth were sectioned buccolingually, in the approximate centre of the restoration (Figure 3).

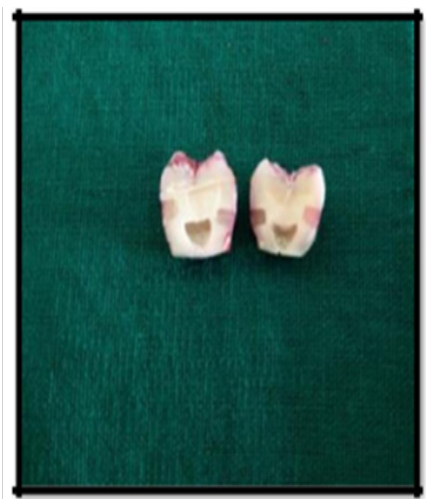

Figure 3 Coronal portion of the teeth were sectioned buccolingually, in the approximate centre of the restoration

Microleakage was assessed for both occlusal (enamel) and gingival (cementum) margins, using a stereomicroscope (Magnus) at original magnification of X16.

The depth of the stain (dye leakage) was judged according to the following scale:

A. No leakage (Figure 4)

B. Penetration less than one half of the length of occlusal/gingival wall (Figure 5)

C. Penetration greater than one half of the length of occlusal/ gingival wall (Figure 6)

D. Penetration up to and along the axial wall (Figure 7)

E. Penetration within the pulp (Figure 7)

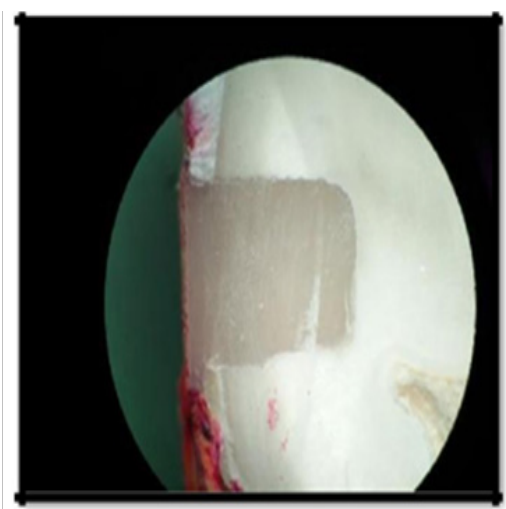

Figure 4 No leakage (score 0). 




Figure 5 Penetration less than one half of the length of occlusal/gingival wall (score I).

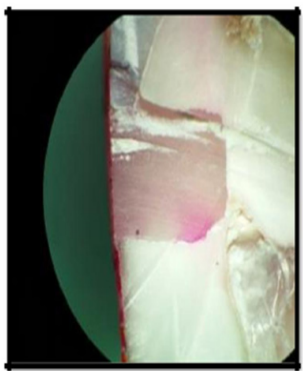

Figure 6 Penetration greater than one half of the length of occlusal/gingival wall (score 2).

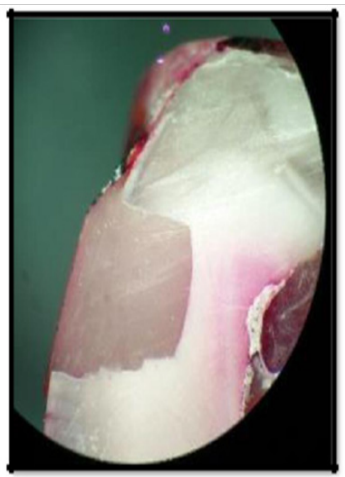

Figure 7 Penetration up to and along the axial wall and Penetration within the pulp (score $3 \& 4$ ).

\section{Results and discussion}

\section{Results}

Control group showed consistently higher leakage values ranging from 3 to 4 whereas the experimental groups exhibited significantly less leakage $(0,1,2)$ (Table 1) (Table 2). Chi-square/Fisher Exact test was used for the significance of study parameters on categorical scale between the groups.

The scores for leakage along the occlusal and gingival margins in the treatment groups were compared using Wilcoxon matched pairs signed rank test. The level of significance was established as $\mathrm{P}<0.05$, for all the tests. Pair wise comparisons for leakage amongst the two experimental groups in both the occlusal and gingival walls showed no statistically significant differences as shown in Graph 1 . However, a statistically significant difference was found between both the experimental groups and their respective controls (Graph 2).
Table I Comparison of leakage pattern in two groups in experiment

\begin{tabular}{|c|c|c|}
\hline $\begin{array}{l}\text { Leakage pattern in experimental } \\
\text { groups }\end{array}$ & Group A & Group B \\
\hline No leakage & $3(30.0 \%)$ & $6(60.0 \%)$ \\
\hline $\begin{array}{l}\text { Penetration less than on half of the } \\
\text { length of occlusal/gingival wall }\end{array}$ & $3(30.0 \%)$ & $4(40.0 \%)$ \\
\hline $\begin{array}{l}\text { Penetration greater than on half of } \\
\text { the length of occlusal/gingival wall }\end{array}$ & $2(20.0 \%)$ & 0 \\
\hline $\begin{array}{l}\text { Penetration up to and along the axial } \\
\text { wall }\end{array}$ & $2(20.0 \%)$ & 0 \\
\hline Penetration within the pulp & 0 & 0 \\
\hline Total & $10(100.0 \%)$ & $10(100.0 \%)$ \\
\hline
\end{tabular}

Table 2 Comparison of leakage pattern in two groups in controls

\begin{tabular}{|c|c|c|}
\hline Leakage pattern in control groups & Group A & Group B \\
\hline No leakage & 0 & 0 \\
\hline $\begin{array}{l}\text { Penetration less than on half of the } \\
\text { length of occlusal/gingival wall }\end{array}$ & 0 & 0 \\
\hline $\begin{array}{l}\text { Penetration greater than on half of the } \\
\text { length of occlusal/gingival wall }\end{array}$ & $\mathrm{I}(10.0 \%)$ & $\mathrm{I}(10.0 \%)$ \\
\hline $\begin{array}{l}\text { Penetration up to and along the axial } \\
\text { wall }\end{array}$ & $4(40.0 \%)$ & $5(50.0 \%)$ \\
\hline Penetration within the pulp & $5(50.0 \%)$ & $4(40.0 \%)$ \\
\hline Total & $10(100.0 \%)$ & $10(100.0 \%)$ \\
\hline
\end{tabular}

P:0.206; Not significant; Fisher exact test

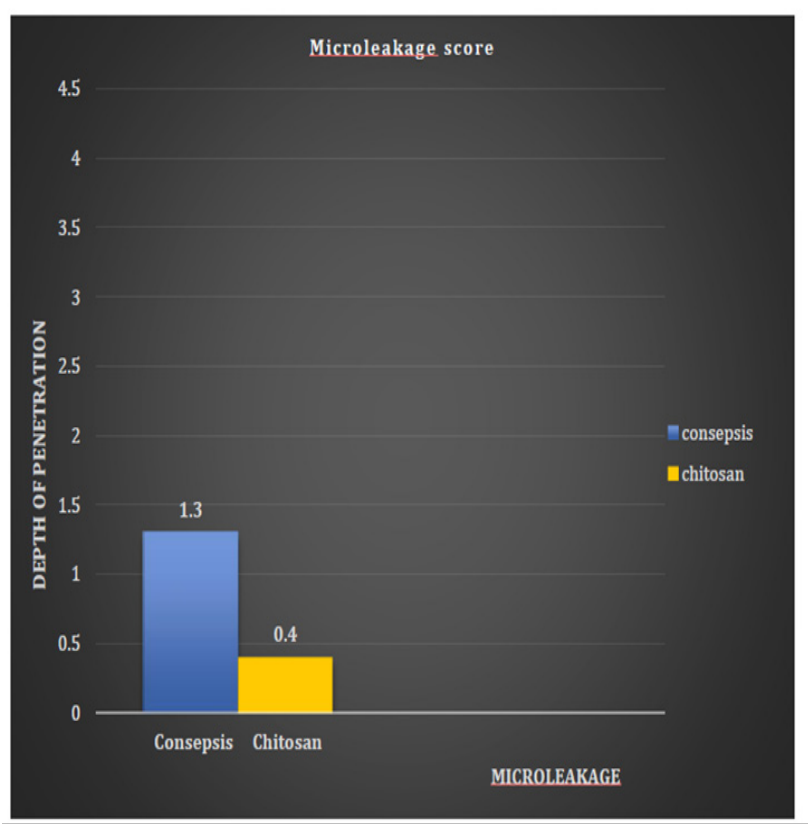

Graph I Comparison among two experimental groups showing microleakage. 


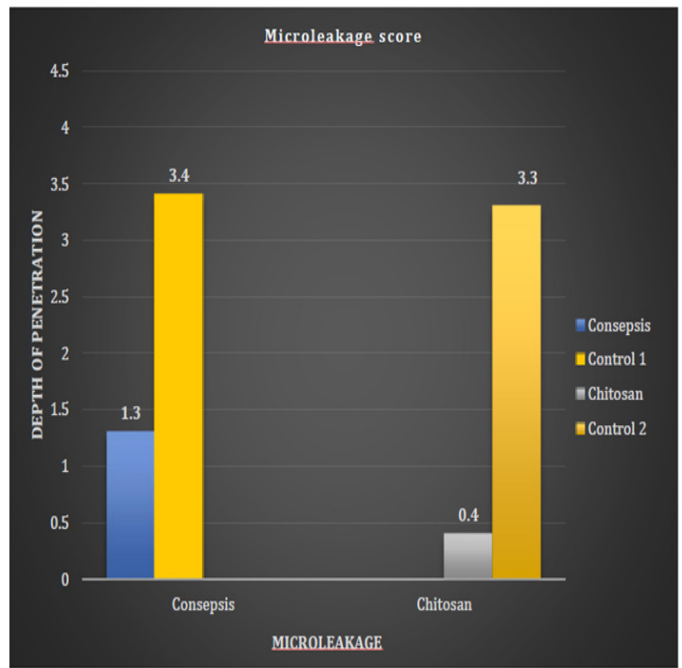

Graph 2 Comparison between experimental groups and control groups showing microleakage.

\section{Discussion}

Historically, it was suggested that dentin should be sterilized before the placement of any restorative material. Many chemicals, such as silver nitrate precipitated with eugenol, thymol, and potassium ferrocyanide, had been proposed for this purpose. The rationale prevailing for this was that any residual microorganisms should be eliminated in order to prevent the potential propagation of caries. Today, it is known that these chemicals are irritating to the pulp when applied to the dentin surface. ${ }^{11}$ Thus, any chemical that is capable of destroying microorganisms may also have a detrimental influence on the pulp. The use of consepsis and chitosan-based disinfectant has been proposed for disinfecting the cavity preparation, prior to its restoration.

A study by Perchyonok ${ }^{12}$ had reported that the antioxidantchitosan hydrogels significantly improved bonding to dentine with or without phosphoric acid treatment. The Chitosan used in our study is a natural carbohydrate polymer derived from the deacetylation of chitin produced commercially from crab and shrimp shell wastes. Numerous studies have shown that chitosan is a biologically safe biopolymer, has been proposed as a bio-adhesive polymer ${ }^{13}$ Most of the current generation disinfectants contain $2 \%$ chlorhexidine gluconate as the primary active ingredient, which is an antiseptic with a wide spectrum of action. Consepsis used in our study contains $2 \%$ chlorhexidine gluconate and has been reported to have better antimicrobial activity.

According to Shafiei et al. ${ }^{14} \mathrm{CHX}$ acts as a preservative on dentin bonding and showed no adverse effect on immediate bond strength and enamel or dentin leakage. The use of cavity disinfectants after tooth preparation and before the application of dentin-bonding agents could help reduce the potential for residual caries and postoperative sensitivity. ${ }^{15}$ However, any positive benefits would be negated if the solutions significantly increased the amount of microleakage, by interfering with the bonding agent's interaction with dentin.

In comparison to the control, both the experimental groups exhibited significantly lower levels of microleakage (Table 3) (Table 4). In the present study, Chitosan showed marginally better resistance to microleakage as compared to consepsis. This could be because of the formation of complexes between chitosan and metal ions in the inorganic dentin which is most probably due to the mechanisms of adsorption, ion exchange and chelation. ${ }^{12}$ Also, $0.12 \%$ and $0.25 \%$ $(\mathrm{w} / \mathrm{w})$ chitosan does not adversely affect adhesive properties of the bonding system. ${ }^{16}$

Table 3 Comparison of leakage pattern in two groups in group A

\begin{tabular}{lll}
\hline Leakage pattern in group A & Experimental & Controls \\
\hline No leakage & $3(30.0 \%)$ & 0 \\
$\begin{array}{l}\text { Penetration less than on half of the } \\
\text { length of occlusal/gingival wall }\end{array}$ & $3(30.0 \%)$ & 0 \\
$\begin{array}{l}\text { Penetration greater than on half of } \\
\text { the length of occlusal/gingival wall }\end{array}$ & $2(20.0 \%)$ & $1(10.0 \%)$ \\
$\begin{array}{l}\text { Penetration up to and along the axial } \\
\text { wall }\end{array}$ & $2(20.0 \%)$ & $4(40.0 \%)$ \\
$\begin{array}{l}\text { Penetration within the pulp } \\
\text { Total }\end{array}$ & 0 & $5(50.0 \%)$ \\
\hline P:0.013*; Significant; Fisher exact test & $10(100.0 \%)$ & $10(100.0 \%)$ \\
\hline
\end{tabular}

Table 4 Comparison of leakage pattern in two groups in group B

\begin{tabular}{lll}
\hline Leakage pattern in group B & Experimental & Controls \\
\hline $\begin{array}{l}\text { No leakage } \\
\begin{array}{l}\text { Penetration less than on half of the } \\
\text { length of occlusal / gingival wall }\end{array}\end{array}$ & $6(60.0 \%)$ & 0 \\
$\begin{array}{l}\text { Penetration greater than on half of the } \\
\text { length of occlusal / gingival wall }\end{array}$ & 0 & 0 \\
$\begin{array}{l}\text { Penetration up to and along the axial } \\
\text { wall }\end{array}$ & 0 & $1(10.0 \%)$ \\
$\begin{array}{l}\text { Penetration within the pulp } \\
\text { Total }\end{array}$ & 0 & $5(50.0 \%)$ \\
\hline
\end{tabular}

P:0.009**; Significant; Fisher exact test

In our study, Consepsis solution also did not adversely affect the sealing ability of Clearfil SE bond., ${ }^{9,17}$ The presence of statistical difference in our study, between the control and the experimental groups treated with chitosan and consepsis before the application of the dentin adhesive systems, in both occlusal and gingival marginal leakage scores, showed that cavities treated without a cavity disinfectant had significant microleakage whereas Chitosan was found to be similar to Consepsis, an established cavity disinfectant in preventing microleakage and was found not to interfere with bonding of composite resin to either dentin or cementum, holds potential to be used as an effective cavity disinfectant prior to restoration with composite resin. The results of our study were in accordance with another study conducted by Meiers et al. ${ }^{9}$

\section{Conclusion}

Within the limitations of this study, it can be concluded that Chitosan was found to be similar to Consepsis, (an established cavity disinfectant) in preventing microleakage and was found not to affect the sealing ability of Clearfil SE Bond or interfere with bonding of composite resin to either dentin or cementum. Also, it holds potential to be used as an effective cavity disinfectant prior to restoration with composite resin.

\section{Acknowledgements}

The authors are thankful to Dr. Usha G, Mr. Bharat, Prime Dental, Ultradent, USA and Kurraray, Japan for providing cavity disinfectants and other materials related to the study. 


\section{Conflict of interest}

The author declares no conflict of interest.

\section{References}

1. Van Meerbeek B, De Munck J, Yoshida Y, et al. Buonocore memorial lecture. Adhesion to enamel and dentin: Current status and future challenges. Oper Dent. 2003;28(3):215-235.

2. Walshaw PR, McComb D. SEM evaluation of the resin-dentin interface with propriety bonding agents in human subjects. $J$ Dent Res. 1994;73(5):1079-1087.

3. Goracci G, Mon G, Bazucchi M. Marginal seal and biocompatibility of a fourth-generation bonding agent. Dent Mat. 1995;11(6):343-347.

4. Perdigao J, Lambrechts P, Van Meerbeek B, et al. The interaction of adhesive systems with human dentin. Am J Dent. 1996;9(4):167-173.

5. Brannstrom M. The cause of post-operative sensitivity and its prevention. J Endod. 1986;12(10):475-481.

6. Gultz J, Do L, Boylan R, Kaim J, et al. Antimicrobial activity of cavity disinfectants. Gen Dent. 1999;47(2):187-190.

7. Brannstrom M, Nyborg H. Cavity treatment with a microbicidal fluoride solution: Growth of bacteria and effect on pulp. J Prosth Dent. 1973;30(3):303-310.

8. Gwinnet AJ. Effect of cavity disinfection on bond strength to dentin. $J$ Esthet Dent. 1992;4:11-13.
9. Meiers JC, Kresin JC. Cavity disinfectants and dentin bonding. Oper Dent. 1996;21(4):153-159.

10. Tulunoglu O, Ayhan H, Olmez A, et al. The effect of cavity disinfectants on microleakage in dentin bonding systems. J Clin Pediatr Dent. 1998;22(4):299-305.

11. Baum L, Phillips RW, Lund MR. Textbook of operative dentistry. Saunders, Philadelphia, USA: Springer; 1995. p. 132-133.

12. Tamara Perchyonok V. Insights into chitosan hydrogels on dentine bond strength and cytotoxicity. Open Journal of Stomatology. 2013;3(1):7582 .

13. Newsletter. Chitosan antibacterial use in dental materials. NIDM. 2015;3:1-2.

14. Shafiei F, Memarpour M, Khajeh F, et al. The effect of chlorhexidine disinfectant on microleakage of adhesive systems in composite restorations. Shiraz Univ Dent J. 2010;11(3):228-234.

15. Al Omari WM, Al Omari QD, Omar R. Effect of cavity disinfection on postoperative sensitivity associated with amalgam restoration. Oper Dent. 2006;31(2):165-170.

16. Elaska SE. Antibacterial activity and adhesive properties of a chitosan-containing dental adhesive. Quintessence Int. 2012;43(7):603-613.

17. Sharma V, Nainan MT, Shivanna V. The effect of cavity disinfectants on the sealing ability of dentin bonding system: An in vitro study. J Conserv Dent. 2009;12(3):109-113. 